\title{
Brief communication: Extended chronology of the Cordón Caulle volcanic eruption beyond 2011 reveals toxic impacts
}

\author{
Werner T. Flueck ${ }^{1,2}$ \\ ${ }^{1}$ CONICET, Argentine National Park Administration, Bariloche, 8400, Argentina \\ ${ }^{2}$ Swiss TPH, Universität Basel, Basel, Switzerland \\ Correspondence to: Werner T. Flueck (wtf@ deerlab.org)
}

Received: 8 May 2016 - Published in Nat. Hazards Earth Syst. Sci. Discuss.: 6 June 2016

Accepted: 28 October 2016 - Published: 10 November 2016

\begin{abstract}
Aside of immediate impacts, the 2011 PuyehueCordón Caulle volcano (PCC) eruption also caused persisting chemical impacts. By 2012, toxicity resulted in overt dental fluorosis in deer, with bone fluoride increasing $>38$-fold to $5175 \mathrm{ppm}$. Sheep, horses and cattle also succumbed to fluorosis. Due to eolian redeposition of tephra, exposure of ruminants continued, bone fluoride reached $10396 \mathrm{ppm}$, and by 2014 skeletal fluorosis was found. Nonskeletal fluorosis resulted in reduced wool growth and major losses among periparturient cattle. Peculiarities of digestive processes make ruminants susceptible to fluoride-containing tephra, which averaged $548 \mathrm{ppm}$ from PCC. Moreover, recent volcanic eruptions causing fluorosis could be aggravated by local iodine deficiency, which increases the incidence and harshness of fluorosis, and deficiency of selenium, which, among other things, also results in secondary deficiency of iodine. Notwithstanding, several measures are available to livestock producers to minimize chemical impacts of fluoride.
\end{abstract}

\section{Introduction}

Volcanic eruptions can affect societies via interactions between natural, technological, and social aspects and result in significant economic impact. Recently, the 2011 eruption of the Puyehue-Cordón Caulle volcano (Chile, PCC) was reviewed by analyzing the chronology of this eruption and its impacts on the population, infrastructures, and the environment. Although in their review Elissondo et al. (2016) described situations like the phenomena of the advancing lava front at a stage occurring in 2013, and cited literature published through 2015, the only mention of chemical impacts was based on two reports from 2011 which stated that, soon after the eruption, no toxicity was found in water and that drinking-water qualities were thus ascertained. Similarly, the description of the impact on animals was limited to the initial effect of tephra (reducing forage availability, eye irritation etc.) based on unpublished reports soon after the eruption.

The present paper provides an update specifically about the toxic impact from the PCC, due to its importance, which commenced soon after the eruption, has persisted until the present and likely continues for years to come.

\section{Background}

Tephra was analyzed soon after the PCC eruption, revealing mostly sodium, aluminium, silicon, iron, oxygen, and potassium (reviewed in Flueck, 2016). Initial concerns included potential chemical impacts, but water-soluble extracts from tephra were judged benign and the drinking of water by animals and humans was considered not to present any risks (Wilson et al., 2013). Although the region affected by tephra resulted in livestock becoming weak and causing deaths of several hundred thousand animals, this was insinuated to stem from blockage of the rumen, inanition, and exorbitant tooth attrition, rather than from poisonous constituents (Wilson et al., 2013). Nonetheless, the first overt manifestations of chemical impacts in wild ruminants were registered in 2012, and these chronological events are expounded next. 


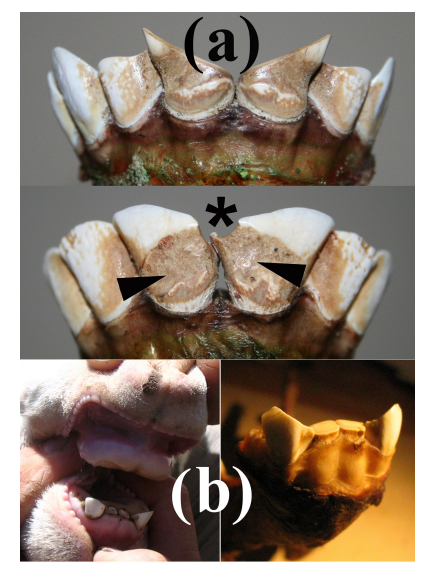

Figure 1. (a) Typical early fluorosis lesions in deer due to the Puyehue-Cordón Caulle volcanic eruption. (b) Typical fluorosis lesions in livestock due to the Puyehue-Cordón Caulle volcanic eruption. The new I1 are already completely worn down as the I2 emerge.

\subsection{PCC: dental fluorosis and the kinetics of fluoride accumulation in wild cervids over time}

The first press release about toxic effects dates from January 2013 when CONICET (National Scientific and Technical Research Council, Buenos Aires) made reference to a study in 2012 documenting cases of subadult deer with overt aberrant tooth development typical of fluoride poisoning (Fig. 1a). Furthermore, fluoride concentrations in bone approached $5180 \mathrm{ppm}$, whereas the average level increased more than $3900 \%$ after exposure to tephra for the first 15.5 months (Flueck and Smith-Flueck, 2013a). Furthermore, fluoride concentrations increased substantially in four age classes, at a rate of about $1000 \mathrm{ppm}$ of $\mathrm{F} \mathrm{yr}^{-1}$ on average. These kinetics of building up fluoride levels over time indicated that the origin of available fluoride was exceedingly effective in causing poisoning (Flueck and SmithFlueck, 2013b). In October and November of 2013 it was documented that some deer, which were occupying areas resulting in higher rates of ingesting tephra, accumulated fluoride at a rate of about $3700 \mathrm{ppm}$ of $\mathrm{F} \mathrm{yr}^{-1}$. With 28 months of exposure, this resulted in bone fluoride levels reaching up to 10396 ppm (Flueck, 2014). Before the PCC, deer had been collected in the same study area and their bones served to check the background concentrations of fluoride which averaged 63 ppm among adults: this compared to $58 \mathrm{ppm}$ of bone fluoride from deer in a study area not affected by tephra from the PCC (Flueck, 2014).

\subsection{PCC: dental fluorosis in domestic livestock}

Subsequent evaluations of livestock showed that these also suffered from the continuous exposure to fluoride via the tephra (Flueck, 2013). Apart from accelerated wear of

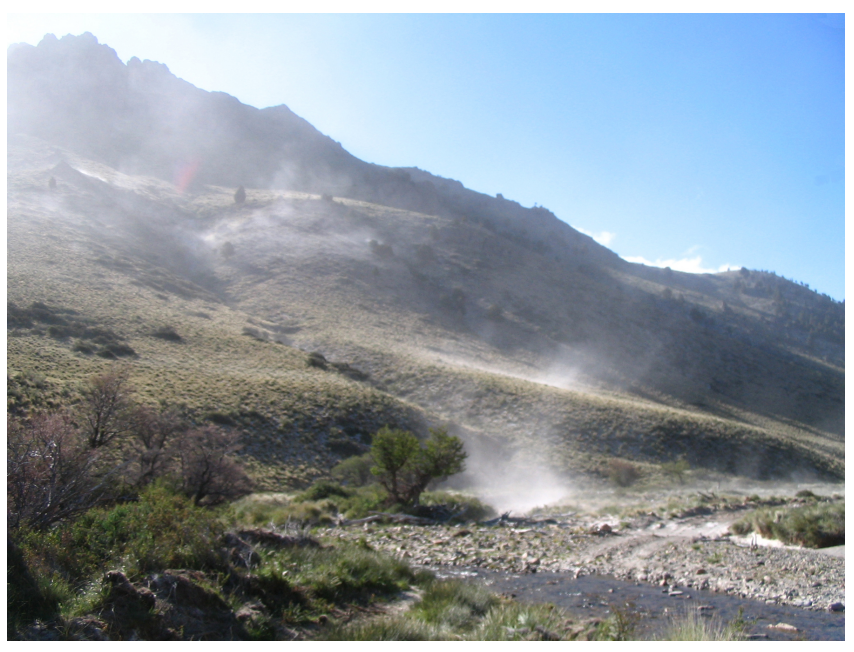

Figure 2. Ecotonal landscape in the affected area. Although known for commonly strong eolian conditions, this was a "calm" day without westerlies: this turbulence is due to daily thermal wind patterns, which shift ashes in any direction.

permanent teeth due to the abrasive character of tephra, subadults displayed even more intense tooth wear as their newly emerged permanent teeth developed under toxic levels of dietary fluoride (Fig. 1b). Bone analyses in herbivores which died shortly after August 2012 and were exposed to tephra some 14-15 months showed for five distinct ranches that sheep averaged 2431, 1604, 1160, 956, and $931 \mathrm{ppm}$ of fluoride, respectively (maximum: $3253 \mathrm{ppm}$ ). Fluoride levels in two horses were 880 and 1198 ppm (Flueck, 2013), and levels in two cows were 1067 and 1337 ppm (W. Flueck, unpublished).

\subsection{PCC: skeletal fluorosis}

Because the east side of the continental divide particularly is exposed to dryer conditions, the tephra succumbs to eolian redeposition. Moreover, as the tephra contains a high concentration of fluoride, it was suggestive that domestic and wild ruminants would continue to be exposed to fluoridecontaining tephra while it remains near the soil surface (Fig. 2). Consequently, by 2014 a male deer was collected which represents a possible first case of skeletal fluorosis (Flueck, 2016). Several skeletal pathologies were found on all available three limbs. Of the long bones, several exhibited exostoses on distal ends and the shaft; a metacarpal was wider by $32 \%$ and shorter by $8 \%$, twisted $25^{\circ}$ compared to normal metacarpals and curving strongly medially, and there were partially eroded articular surfaces (Fig. 3i). The male thus exhibited osseous changes which are compatible with those described for chronic fluoride poisoning. Suttie et al. (1972) found that all cattle with fluoride levels between 7000 and $15000 \mathrm{ppm}$ expressed skeletal fluorosis. 


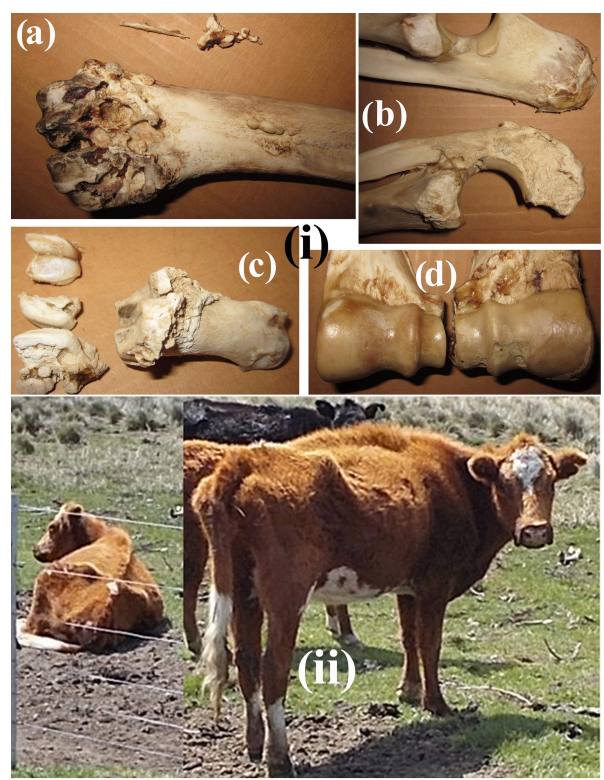

Figure 3. (i) Skeletal fluorosis in deer: (a) deformed metacarpal with exostoses and calcified tendons, (b) ulna with various pathologies next to a normal one, (c) proximal sesamoid bones and first phalange with exostoses, (d) distal humerus with exostoses and eroded articulation next to normal one. (ii) Numerous periparturient cattle died in early spring of 2015 even though the winter had been very mild. This cow could barely stand up and make a few steps.

\subsection{PCC: nonskeletal fluorosis (reviewed in Flueck, 2016)}

In the region affected by the PCC eruption of 4 June 2011, the sheep wool growing period stops by late winter (AugustSeptember). The subsequent shearing initiated thereafter hence occurred about 3 to 4 months after this fallout of PCC tephra, when a substantial reduction in wool production was observed (Easdale et al., 2014). The accelerated build-up of fluoride in ruminants exposed to PCC tephra (Flueck, 2014) coincides with Grace et al. (2007), who showed that bone fluoride concentration in sheep incremented in only 3 months from 160 to about $2300 \mathrm{ppm}$. The reduction in wool production is explained by particular biochemical links between wool growth and fluoride poisoning. For example, it is well recognized that fluoride poisoning reduces levels of serum triiodothyronine and thyroxine, and that ruminants develop anaemia, eosinophilia of leukocytes, and hypothyroidism. Hyperthyroidism in fact had been treated successfully using fluoride. Fluoride poisoning in sheep also was shown to cause oxidative stress and affect lipid peroxidation. Furthermore, the fact that chemical impacts from tephra have caused reduced wool production in Ovis spp. is widely referenced in the literature.

Although the winter of 2015 brought very little snow and had mild temperatures, ranches had suffered major casualties among periparturient cattle (during October 2015, Fig. 3ii). Some cows died during parturition and were unable to expel the fetus, but often both the mother and a newborn neonate nearby were found dead. The cows had a mean bone fluoride level of 2159 ppm (maximum 4517 ppm, Flueck, 2016). These outcomes are compatible with fluoride causing peripartum losses in other herbivores (Krook and Maylin, 1979; Susheela and Bhatnagar, 2002; Choubisa, 2013, 2015). It has been reported numerous times that poor nutritional conditions of animals exacerbate the effect of toxic levels of fluoride (Susheela and Bhatnagar, 2002). Concurrently reduced forage production due to dry conditions thus resulted in frequent overstocking conditions and its sequela on average body conditions, which in part may explain the mortalities at parturition.

\subsection{PCC: venues of ingesting fluoride (reviewed in Flueck, 2016)}

Contaminated water is a frequent scenario. However, all water analyses regarding the PCC reported so far have not detected unacceptable concentrations of fluoride.

Forage plants were blanketed and continue to be reblanketed by aerially deposited tephra, resulting in direct ingestion by herbivores. Rain also causes splattering of contaminated soil which adheres to the lower strata. Large amounts of tephra can be ingested via grooming, and by ingesting large amounts of soil (in sheep as much as $14 \%$ dry matter intake; or $300 \mathrm{~g} \mathrm{day}^{-1}$ ). These factors result in continuous passive absorption of fluoride by the herbivore.

The forage plant itself presents a potential source of excessive ingestion of fluoride. Evidently, from the PCC event only one analysis exists on fluoride concentrations in forage species and soft tissues of animals: forage fluoride levels in Chile were more than $400 \%$ higher than accepted concentrations, whereas livestock blood levels were also increased. Instructionally, when the Lonquimay volcano (nearby at $200 \mathrm{~km}$ north of PCC) erupted earlier in 1988, within 3 months it produced fluoride poisoning in livestock, and forage plants had toxic levels during the 2 years of posteruption monitoring such that these elevated fluoride levels alone were judged to be a danger to herbivores.

\subsection{PCC: chemical characteristics of tephra}

As only reports of water leachate experiments were available regarding fluoride, we samples ashes in 10 different sites. Whereas water leachates also resulted in low fluoride level, in agreement with the 2011 reports, the average total fluoride level in tephra was 548 ppm (Flueck, 2016).

\subsection{Ruminant digestion: a special extraction process of fluoride (reviewed in Flueck, 2016)}

The unique digestive system of ruminants seems to explain their pronounced susceptibility to toxic impacts from exces- 
sive dietary fluoride, like through the ingestion of fluoridecontaining tephra. Ruminants have a truly elaborate physiochemical system for processing food compounds. The rumination process implies the regurgitation of stomach contents to re-masticate and diminish the particle size. The process results in pulverization of tephra, which explains the accelerated tooth wear. However, it also increases the surface-areato-volume ratio, which effectively liberates more fluoride. Besides, the re-mastication happens in a chemical environment dominated by saliva and is thus very alkaline $(\mathrm{pH}$ of 8.2-8.5). This digestion system is dominated by rumination as shown by the $20-25$ chews before each swallow, and the ample saliva production to replace that which is swallowed every time. Cattle may produce saliva on the order of 100 $200 \mathrm{~L} \mathrm{day}^{-1}$ or more. Thus, one key step in fluoride mass balance in ruminants relates to the substantially facilitated solubility of fluoride in alkaline environments. Then the mixture enters the rumen after swallowing, representing basically a water-based nearly neutral extraction system, although containing various solutes. Lastly, the mixture ends in the abomasum with the final digestion at a low $\mathrm{pH}$ of 1-2. Again, fluoride solubility is greatly enhanced under acidic conditions as compared to neutral media like water. Therefore, initial analyses done on surface water and via water-based leachates of PCC tephra did not provide any clues of future fluoride intoxication among ruminants. It is clear, therefore, that ruminant susceptibleness relates to their food processing: (1) repeated cycles of re-mastication and reduction of tephra size (resulting in accelerated tooth wear), (2) exhaustive mixing of alkaline saliva with tephra during many rumination cycles, (3) extraction in the near-neutral water-soluble rumen environment, and (4) final extraction in the highly acidic abomasal environment.

\subsection{Comparison with other volcanic eruptions in the region}

The 2011 eruption of PCC was also compared to the 1991 Hudson and the 2008 Chaitén eruptions (Elissondo et al., 2016). Although impacts from fluoride were not mentioned, deer dying 6 years after the Chaiten eruption still had bone fluoride levels of over $3000 \mathrm{ppm}$ and osteopathological lesions compatible with fluorosis (Flueck et al., unpublished). Although early analyses of tephra from the Hudson revealed high fluoride levels, the many thousands of deaths among sheep were ascribed to physical properties of tephra - not chemical ones (Rubin et al., 1994). However, considering that the study was done only 1 month following the eruption, it would not have allowed the detection of even mild chronic fluoride poisoning, because chronic fluoride poisoning develops generally in a gradual and insidious manner. The 2015 eruption of the volcano Calbuco was also mentioned. The role of its tephra in contributing to fluoride exposure was recently confirmed by the average concentration of $352 \mathrm{ppm}$ via $\mathrm{NaOH}$ digestion, while $204 \mathrm{ppm}$ resulted from $\mathrm{HCl}$ di- gestion, and only $29 \mathrm{ppm}$ was found upon water leachates (Flueck, 2016).

\section{Discussion and conclusions}

Impact assessments after a volcanic eruption, including the medium- and long-term effects, are useful to better forecast the consequences of future eruptions. Contamination with fluoride has resulted in profound impact on livestock from the 1988 Lonquimay volcano eruption (near the PCC). Even though fluoride in leachate was high, fluorosis has been discarded for the Hudson event based on one survey done only 1 month after the eruption: therefore, medium- and long-term chronic effects remained undocumented. As the immediate effects of recent volcanic eruptions were commonly dominated by a reduction of available forage, physical impacts on eyes and from ash loads, and often in water stressed environments, the impact on animals was commonly considered to be from only these physical properties of the tephra, rather than chemical ones.

The mostly subclinical and chronic effects from fluoride toxicity via tephra from these recent volcanic eruptions may explain the apparent lack of appreciating their importance, as well as the absence of further studies on domestic and wild animals and their habitats. Future management decisions, considering such long-lasting chemical impacts, would benefit from such additional investigations. For instance, no information has been generated about impacts on protected native camelids (Lama guanicoe) that coexist in areas with deer and livestock with overt fluoride poisoning. There are no reports on fluoride contents of forage plants from Argentine areas impacted by tephra (PCC and Calbuco events), although root uptake of fluoride can contaminate forage plants and may thus create an additional important source for herbivore intoxication. A recent study on tephra from the PCC concluded that the leachate results corroborate $\mathrm{F}$ toxicity as a contributing factor to large-scale ruminant deaths and chronic fluorosis in wild deer (Stewart et al., 2016).

Moreover, the effects from fluoride poisoning are expected to be exacerbated by iodine and selenium deficiencies in the large area impacted by these recent volcanic eruptions (Matamoros et al., 2003; Flueck et al., 2014). The incidence of dental fluorosis and severity of damages may increase with iodine deficiency, while secondary iodine deficiency results from selenium deficiency, among other things (Flueck et al., 2012).

To improve preparedness of livestock producers, it is essential that not only the water supplies but also their livestock, tephra, and forage be analyzed and monitored for fluoride. Among several measures aimed at reducing the toxic impact on the animals, a key management option is to feed non-contaminated food to young animals during their development of permanent teeth. This would result in the individuals gaining some extra years of life by slowing down the 
wear on healthy teeth. These animals could either be moved to uncontaminated sites during this growth phase or be given imported feed. A second measure is providing supplemental nutrients as practiced in areas affected by excess fluoride. For instance, food containing ample amounts of calcium $(\mathrm{Ca})$ and vitamin $\mathrm{C}$ helps counteract $\mathrm{F}$ toxicity. Thus, to overcome these problems, livestock owners could consider the following: chemical feed supplementation to reduce the absorption of fluoride and to counteract the effects of absorbed fluoride (e.g., aluminum sulfate given daily, $\mathrm{Ca}$ salts given intravenously); dry season nutrient supplementation; grass cultivation and/or low fluoride grass storage for use for supplementary feeding in the dry season; and the mechanical trimming of deformed sawteeth (Ulemale et al., 2010; Choubisa, 2015). As bone meal is a rich source of fluoride, it must be used cautiously in the feed and stem from production areas with low fluoride exposure (Ulemale et al., 2010).

Acknowledgements. I would like to thank A. Rigalli and the anonymous referee for their constructive comments, as well as the executive editors of Natural Hazards and Earth System Sciences for kindly covering the publication costs of this article.

Edited by: G. Macedonio

Reviewed by: A. Rigalli and one anonymous referee

\section{References}

Choubisa, A. L.: Fluorotoxicosis in diverse species of domestic animals inhabiting areas with high fluoride in drinking water of Rajasthan, India, P. Natl. Acad. Sci. USA, 83, 317-321, 2013.

Choubisa, A. L.: Industrial fluorosis in domestic goats (Capra hircus), Rajasthan, India, Fluoride, 48, 105-112, 2015.

Easdale, M. H., Sacchero, D., Vigna, M., and Willems, P.: Assessing the magnitude of impact of volcanic ash deposits on Merino wool production and fibre traits in the context of a drought in Northwest Patagonia, Argentina, Rangeland J., 36, 143-149, 2014.

Elissondo, M., Baumann, V., Bonadonna, C., Pistolesi, M., Cioni, R., Bertagnini, A., Biass, S., Herrero, J.-C., and Gonzalez, R.: Chronology and impact of the 2011 Cordón Caulle eruption, Chile, Nat. Hazards Earth Syst. Sci., 16, 675-704, doi:10.5194/nhess-16-675-2016, 2016.

Flueck, W. T.: Effects of fluoride intoxication on teeth of livestock due to a recent volcanic eruption in Patagonia, Argentina, Online J. Vet. Res., 17, 167-176, 2013.
Flueck, W. T.: Continuing impacts on red deer from a volcanic eruption in 2011, Eur. J. Wildlife Res., 60, 699-702, 2014.

Flueck, W. T.: The impact of recent volcanic ash depositions on herbivores in Patagonia: a review, Rangeland J., 38, 27-34, 2016.

Flueck, W. T. and Smith-Flueck, J. M.: Severe dental fluorosis in juvenile deer linked to a recent volcanic eruption in Patagonia, J. Wildlife Dis., 49, 355-366, 2013 a.

Flueck, W. T. and Smith-Flueck, J. M.: Temporal kinetics of fluoride accumulation: from fetal to adult deer, Eur. J. Wildlife Res., 59, 899-903, 2013b.

Flueck, W. T., Smith-Flueck, J. M., Mionczynski, J., and Mincher, B. J.: The implications of selenium deficiency for wild herbivore conservation, a review, Eur. J. Wildl. Res., 58, 761-780, 2012.

Flueck, W. T., Smith-Flueck, J. M., Mincher, B. J., and Winkel, L. H. E.: An alternative interpretation of plasma selenium data from endangered Patagonian huemul deer (Hippocamelus bisulcus), J. Wildlife Dis., 50, 1003-1004, 2014.

Grace, N. D., Loganathan, P., and Hedley, M. J.: The effect of a temporal change in ingestion rates of fluorine $(F)$ in soil on the concentration of $\mathrm{F}$ in serum and bone of young sheep, NZ Vet. J., 55, 77-80, 2007.

Krook, L. P. and Maylin, G. A.: Industrial fluoride pollution. Chronic fluoride poisoning in Cornwall Island cattle, Cornell Vet., 69, 1-70, 1979.

Matamoros, R., Contreras, P. A., Wittwer, F., and Mayorga, M. I.: Hypothyroidism in ruminants, Arch. Med. Vet., 35, 1-11, 2003.

Rubin, C. H., Noji, E. K., Seligman, P. J., Holtz, J. L., Grande, J., and Vittani, F.: Evaluating a fluorosis hazard after a volcanic eruption, Arch. Environ. Health, 49, 395-401, 1994.

Stewart, C., Craig, H. M., Gaw, S., Wilson, T., Villarosa, G., Outes, V., Cronin, S., and Oze, C.: Fate and agricultural consequences of leachable elements added to the environment from the 2011 Cordón Caulle tephra fall, J. Volcanol. Geotherm. Res., doi:10.1016/j.jvolgeores.2016.09.017, 2016.

Susheela, A. K. and Bhatnagar, M.: Reversal of fluoride induced cell injury through elimination of fluoride and consumption of diet rich in essential nutrients and antioxidants, Mol. Cell. Biochem., 234/235, 335-340, 2002.

Suttie, J. W., Carlson, J. R., and Faltin, E. C.: Effects of alternating periods of high- and low-fluoride ingestion on dairy cattle, $\mathrm{J}$. Dairy Sci., 55, 790-804, 1972.

Ulemale, A. H., Kulkarni, M. D., Yadav, G. B., Samant, S. R., Komatwar, S. J., and Khanvilkar, A. V.: Fluorosis in cattle, Vet. World, 3, 526-527, 2010.

Wilson, T., Stewart, C., Bickerton, H., Baxter, P., Outes, A. V., Villarosa, G., and Rovere, E.: Impacts of the June 2011 PuyehueCordón Caulle volcanic complex eruption on urban infrastructure, agriculture and public health, GNS Sci. Rep., 2012, 1-88, 2013. 